\title{
Application of UV absorbance and fluorescence indicators to assess the formation of biodegradable dissolved organic carbon and bromate during ozonation
}

Wen-Tao Li ${ }^{\text {a, b, }}$, , Meng-Jie Cao ${ }^{\text {b }}$, Tessora Young ${ }^{b}$, Barbara Ruffino ${ }^{c}$, Michael Dodd $^{\mathrm{b}}$, Ai-Min Li ${ }^{\mathrm{a}, *}$, Gregory Korshin ${ }^{\mathrm{b}}$

a State Key Laboratory of Pollution Control and Resources Reuse, School of the Environment, Nanjing University, Nanjing, 210023, China

${ }^{\mathrm{b}}$ Department of Civil \& Environmental Engineering, University of Washington, Box 352700, Seattle, WA 98195-2700, United States

${ }^{c}$ Department of Environment, Land and Infrastructure Engineering, Politecnico di Torino, Corso Duca degli Abruzzi, 2410129 Torino, Italy

CORRESPONDING AUTHOR FOOTNOTE :

Prof. Ai-Min Li

Email: liaimin@nju.edu.cn

Wen-Tao Li

Email: liwentaoepa@hotmail.com; liwentaonju@163.com 
Abstract:

This study examined the significance of changes of UV absorbance and fluorescence of dissolved organic matter (DOM) as surrogate indicators for assessing the formation of bromate and biodegradable dissolved organic carbon (BDOC) during the ozonation of surface water and wastewater effluent. Spectroscopic monitoring was carried out using benchtop UV/Vis and fluorescence spectrophotometers and a newly developed miniature LED UV/fluorescence sensor capable of rapidly measuring UVA280 and protein-like and humic-like fluorescence. With the increase of $\mathrm{O}_{3} / \mathrm{DOC}$ mass ratio, the plots of BDOC formation were characterized of initial lag, transition slope and final plateau. With the decrease of UV absorbance and fluorescence, BDOC concentrations initially increased slowly and then rose more noticeably. Inflection points in plots of BDOC versus changes of spectroscopic indicators were close to $35-45 \%$ loss of UVA254 or UVA280 and $75-85 \%$ loss of humic-like fluorescence. According to the data from size exclusion chromatography (SEC) with organic carbon detection and 2D synchronous correlation analyses, DOM fractions assigned to operationally defined large biopolymers (apparent molecular weight, AMW>20 kDa) and medium AMW humic substances (AMW 5.5-20 kDa) were transformed into medium-size building blocks (AMW 3-5.5 kDa) and other smaller AMW species $(\mathrm{AMW}<3 \mathrm{kDa})$ associated with $\mathrm{BDOC}$ at increasing $\mathrm{O}_{3} / \mathrm{DOC}$ ratios. Appreciable bromate formation was observed only after the values of UVA254, UVA280 and humic-like fluorescence in $\mathrm{O}_{3}$-treated samples were decreased by $45-55 \%, 50-60 \%$ and $86-92 \%$ relative to their respective initial levels. No significant differences in 
23 plots of bromate concentrations versus decreases of humic-like fluorescence were 24 observed for surface water and wastewater effluent samples. This was in contrast with 25 the plots of bromate concentration versus UVA254 and UVA280 which exhibited 26 sensitivity to varying initial bromide concentrations in the investigated water matrixes.

27 These results suggest that measurements of humic-like fluorescence can provide a 28 useful supplement to UVA indices for characterization of ozonation processes.

29 Keywords: ozonation; biodegradable dissolved organic carbon; bromate; 30 spectroscopic indicator; humic substances; online fluorescence sensor 


\section{Introduction}

Ozonation has been widely used in drinking water and wastewater treatment for disinfection and oxidation purposes (Reungoat et al. 2012, von Gunten 2003a, b, Zimmermann et al. 2011). Extensive studies have shown that ozonation results in significant elimination of adverse biological effects of many organic micropollutants (e.g., endocrine disrupting chemicals, antibiotics, and pharmaceuticals) as well as removal of color, odor and taste (Dodd et al. 2009, Hollender et al. 2009, Huber et al. 2005, Lee et al. 2012, Liu et al. 2012a, Nakada et al. 2007, Peter and von Gunten 2007).

Ozone exposures required for disinfection and oxidation may result in the formation of undesirable organic and inorganic byproducts, including various disinfection byproducts (DBPs) and biodegradable dissolved organic carbon (BDOC) (von Gunten 2003b, Wert et al. 2007). Ozonation has been shown to convert relatively refractory components of dissolved organic matter (DOM) into BDOC (e.g., aldehydes, carboxylic acids, ketones and etc.) without a significant decrease in overall dissolved organic carbon (DOC) concentration (Liu et al. 2015, Nishijima et al. 2003, Wert et al. 2007). The ozonation-derived BDOC in turn largely defines the biological stability of ozonated water, as it can contribute to increases in bacterial regrowth in drinking water distribution systems or wastewater effluent receiving waters (Escobar and Randall 2001). As a result, ozonation is usually combined with a subsequent process of biological filtration to consume BDOC before the treated water is conveyed into a distribution system or a receiving water body. In this context, 
characterization of changes of molecular weights (MW) of DOM and evaluation of BDOC formation may provide a better understanding of integrated $\mathrm{O}_{3}$ biofiltration processes for DOC removal.

In addition, ozonation of bromide-containing water or wastewater leads to the formation of bromate (von Gunten and Oliveras 1998). Bromate is classified as a probable or likely human carcinogen, and many countries have established the maximum allowable level of bromate in drinking water at $10 \mu \mathrm{g} / \mathrm{L}$ (Butler et al. 2005). Unlike many organic DBPs, bromate is relatively stable and is difficult to remove using conventional treatment technologies (Butler et al. 2005, Nie et al. 2014). Although ecological impacts of bromate formation during wastewater ozonation are uncertain, the potential public health implications of bromate formation in potable water reuse scenarios utilizing ozonation could be significant. Hence it is of substantial interest to develop tools for better predicting and controlling bromate concentrations formed during both drinking water and wastewater ozonation.

The formation of BDOC and bromate, as well as the elimination of micropollutants, are directly related to the ozone exposure $\left(\int_{0}^{t}\left[O_{3}\right] d t\right)$; that is, the time-dependent ozone concentration integrated over exposure time. An optimization of the ozone exposure is necessary to maximize the effect of oxidation and minimize the formation of undesired DBPs, especially $\mathrm{BrO}_{3}{ }^{-}$. However, for wastewater effluents, it is difficult to measure a dissolved $\mathrm{O}_{3}$ residual during the initial $\mathrm{O}_{3}$ demand stage (Gerrity et al. 2012, Wert et al. 2009). Additionally, direct analyses of BDOC and bromate are time-consuming and expensive. Therefore, the development of surrogate 
parameters for frequent online monitoring to enable more automated controls of ozone dosage is warranted. For example, the California Department of Public Health recently published a revised set of draft regulations for groundwater replenishment, which requires full advanced treatment facilities to identify at least one surrogate parameter that can be monitored continuously (Chon et al. 2015, Gerrity et al. 2012).

A number of studies have examined the performance of spectroscopic indicators, such as color, differential UV absorbance (UVA) and/or total fluorescence, and shown that such indicators were correlated with the removal efficiencies of organic micropollutants during ozonation (Gerrity et al. 2012, Li et al. 2016b, Liu et al. 2012b, Nanaboina and Korshin 2010, Wert et al. 2009). Recently, Chon et al. (2015) applied the concept of electron donating capacity of DOM combined with UVA254 measurements to evaluate the degradation of micropollutants and the formation of bromate. Other studies have assessed the use of UVA254 and related indices to quantify the formation of individual ozonation byproducts associated with BDOC (Liu et al. 2012a).

Measurements of UV absorbance at $280 \mathrm{~nm}$ by means of UV light emitting diodes (LEDs) provide an attractive, energy-efficient alternative to conventional UVA254 monitoring (Bridgeman et al. 2015, Tedetti et al. 2013). UVA280 has previously been found to correlate well with DOM molecular weight and aromaticity and exhibit lower spectral overlap than UVA254 with inorganic species such as $\mathrm{NO}_{3}{ }^{-}$ and $\mathrm{NO}_{2}^{-}$that may interfere with measurements in many waters (Chin et al. 1994). In addition, measurements of DOM fluorescence at selected excitation and emission 
wavelengths provide a useful complement to UVA280 since fluorescence detection can also be implemented using LEDs and can enable more selective monitoring of chemically reactive protein-like and humic-like DOM components (Fimmen et al. 2007, Henderson et al. 2009). We recently demonstrated the use of a miniaturized LED UV/fluorescence sensor - capable of online measurement of UVA280, as well as protein-like and humic-like fluorescence - to predict DBP formation during chlorination (Li et al. 2016a).

The present study employs a sensor of this type to determine whether UVA280 and fluorescence indices may be used to develop correlations with BDOC and bromate formed during the ozonation of surface water and wastewater. To this end, degradation of DOM chromophores and fluorophores, MW changes, and formation of BDOC and bromate were examined during ozonation of a set of surface water and wastewater matrixes with varying initial bromide concentrations.

\section{Material and methods}

\subsection{Water matrixes and reagents}

Three water matrixes were used in the experiments described below. Secondary municipal wastewater effluent samples were taken from the West Point Treatment Plant in King County, WA (WWTP-I on Dec $14^{\text {th }}, 2015$ and WWTP-II on Feb $28^{\text {th }}$, 2016). This plant uses high-rate oxygen activated sludge technology without denitrification. The surface water was sampled from Lake Pleasant, which is a brown water eutrophic lake in Bothell, WA. Basic water characteristics of these waters are 
shown in Table 1. All the water samples were immediately filtered through a $0.45 \mu \mathrm{m}$ membrane upon collection and stored at $4{ }^{\circ} \mathrm{C}$ before use.

The following chemicals were used in this study: sodium bromide (Sigma-Aldrich, >99\%), sodium bromate (Sigma-Aldrich, >99\%), polyethylene glycol standards (Alfa Aesar), methylamine solution (Sigma-Aldrich, 40 wt. \% in $\mathrm{H}_{2} \mathrm{O}$ ), and potassium indigotrisulfonate (Sigma-Aldrich).

\subsection{Ozonation batch experiments}

Five semi-batch ozonation experiments were performed at room temperature (25 $\pm 2{ }^{\circ} \mathrm{C}$ ) with the three water matrixes mentioned above to explore the formation of BDOC and bromate and evolution of spectroscopic indices during exposure to ozone. For the WWTP-I water matrix (DOC $5.82 \mathrm{mg} / \mathrm{L}$ ), three semi-batch experiments were undertaken with spiked bromide concentrations of $50 \mu \mathrm{g} / \mathrm{L}$ (WWTP-A, $322.9 \mu \mathrm{g} / \mathrm{L}$ total $\mathrm{Br}^{-}$), $100 \mu \mathrm{g} / \mathrm{L}$ (WWTP-B, $373.8 \mu \mathrm{g} / \mathrm{L}$ total $\mathrm{Br}^{-}$) and $200 \mu \mathrm{g} / \mathrm{L} \mathrm{Br}^{-}$(WWTP-C, $491.6 \mu \mathrm{g} / \mathrm{L}$ total $\left.\mathrm{Br}^{-}\right)$respectively, to explore effects of initial $\mathrm{Br}^{-}$concentration. For the WWTP-II water matrix (DOC $6.93 \mathrm{mg} / \mathrm{L}$ ), one ozonation semi-batch experiment was performed using a $100 \mu \mathrm{g} / \mathrm{L} \mathrm{Br}^{-}$spike (WWTP-D, $301.5 \mu \mathrm{g} / \mathrm{L}$ total $\mathrm{Br}^{-}$) as a comparison with the WWTP-I experiments. Because Lake Pleasant water had a high DOC concentration $(14.87 \mathrm{mg} / \mathrm{L})$, the water was diluted 2.5 times with Milli-Q water and spiked with $100 \mu \mathrm{g} / \mathrm{L} \mathrm{Br}^{-}\left(\mathrm{LP}, 5.98 \mathrm{mg} / \mathrm{L}\right.$ DOC and $116.1 \mu \mathrm{g} / \mathrm{L}$ total $\mathrm{Br}^{-}$).

Ozone was generated by an oxygen-fed ozonator (IN USA AC-2025; Norwood, MA, USA). The feed gas stream containing ozone was bubbled through $200 \mathrm{~mL}$ 
WWTP effluent or $250 \mathrm{~mL}$ LP water samples contained in a $500 \mathrm{~mL}$ borosilicate glass gas-washing bottle using a sintered glass gas diffuser at a flow rate of $\sim 550$ $\mathrm{ml} / \mathrm{min}$. In each batch experiment, the ozone doses were varied as a function of ozonation times which were $0,2,5,10,15,20,25^{*}, 30,40,50^{*}, 60,100,180$ and $300^{* *}$ s ( ${ }^{*}$ specific for LP series and ${ }^{* *}$ specific for WWTP series). The residual $\mathrm{O}_{3}$ concentrations in ozonated samples were immediately measured according to the standard indigo method (Bader and Hoigné 1981), where $1 \mathrm{~mL}$ of ozonated sample was immediately spiked into glass vials containing $9 \mathrm{~mL}$ indigo solution, and then analyzed for residual absorbance at $600 \mathrm{~nm}$ by UV-Vis spectroscopy. The remainder of the ozonated sample volumes was transferred into $250 \mathrm{~mL}$ glass bottles with caps. UVA and fluorescence indicators were measured at least 2 hours after ozonation, allowing the residual ozone to naturally decay without adding any quenching agent. Then the samples were stored at $4{ }^{\circ} \mathrm{C}$ before other analyses, which were done within 5 days for each batch.

Compared with directly spiking aliquots of ozone stock (Chon et al. 2015, Gerrity et al. 2012), the semi-batch ozonation experiment has no dilution effect on the samples, which facilitates the measurement of BDOC. However, the determination of ozone dose becomes another important issue, as the rate of ozone mass transferred into water phase may change as a function of time. As shown in Figure S1, the transferred/absorbed ozone concentrations as a function of time were calculated based on measurements of the differential $\mathrm{O}_{3}$ concentrations between the feed gas and off-gas streams, where the gaseous $\mathrm{O}_{3}$ concentrations were measured by the modified 
indigo method (Chiou et al. 1995).

\subsection{Batch biodegradation experiments}

BDOC measurements were performed by quantifying the gross amount of DOC degraded by an inoculum of suspended activated sludge over a predetermined period of time (Escobar and Randall 2001). In this study, a requisite amount of activated sludge from a WWTP was initially acclimated with glucose for 3 days. The acclimated activated sludge was washed by centrifugation and resuspended in deionized water 5 times prior to harvesting for BDOC measurements. Then $50 \mathrm{~mL}$ centrifuge tubes were filled with $40 \mathrm{ml}$ water samples and spiked with $1 \mathrm{~mL}$ of the harvested activated sludge. The BDOC tests were conducted in duplicate and compared with results obtained using Milli-Q water as a blank control. A $200 \mathrm{mg} / \mathrm{L}$ dry biomass concentration was used in the tests. This dose was determined by weighing the biomass collected from ten test tubes after BDOC experiments; the biomass was dried at $105{ }^{\circ} \mathrm{C}$ before weighing. The inoculated centrifuge tubes were placed in an incubated shaker at $90 \mathrm{rpm}$ and $25^{\circ} \mathrm{C}$ for a period of 4 hours, following which the samples were centrifuged and the supernatants filtered through a $0.45 \mu \mathrm{m}$ PTFE filter for subsequent DOC and molecular weight analysis. The measured BDOC reflects the rapidly biodegradable fraction of BDOC that can be effectively removed by biofiltration; this fraction is thus referred to as $\mathrm{BDOC}_{\text {rapid }}$ henceforth (Black and Berube 2014).

\subsection{UV absorbance and fluorescence analysis}


A HORIBA Aqualog spectrometer was used to simultaneously measure

fluorescence EEM (Ex 220-450 nm / Em 245-825 nm) and UV absorbance spectra $(220-450 \mathrm{~nm})$. The samples' EEMs were automatically corrected for Raman scattering by subtracting the EEM of the water blank from the EEM of any surface water or wastewater sample. Inner filter effects were corrected using the instrument's software that utilized applicable absorbance data.

The prototype LED UV/fluorescence sensor described in more detail in ( $\mathrm{Li}$ et al. 2016a) uses a UV LED (280 $\pm 5 \mathrm{~nm})$ as a light source and a photodiode to measure the intensity of light passing the cuvette. For fluorescence detection, the sensor uses blue light sensitive photodiodes combined with bandpass filters (330-355 nm and $415-490 \mathrm{~nm}$ ) positioned at $90^{\circ}$ relative to the excitation beam to detect the protein-like and humic-like fluorescence, respectively. Inner filter effects in fluorescence signals detected by the sensor were corrected using the UVA280 values.

\subsection{Molecular weight analysis}

Analyses of DOC molecular weight distributions were performed by means of size exclusion chromatography with online carbon detection (SEC-OCD). These measurements utilized a DIONEX Ultimate3000 high-pressure liquid chromatography (HPLC) system coupled with an online organic carbon detector (Turbo Sievers 900 Portable TOC Analyzer, GE). A TOSOH Bioscience Toyopearl HW-50S size exclusion column was installed to separate DOM components with varying apparent MWs. The injection volume was $100 \mu \mathrm{L}$, and the column was eluted with $1 \mathrm{~mL} / \mathrm{min}$ 
203

phosphate buffer $\left(1.5 \mathrm{~g} / \mathrm{L} \mathrm{Na} \mathrm{HPO}_{4} * 2 \mathrm{H}_{2} \mathrm{O}+2.5 \mathrm{~g} / \mathrm{L} \mathrm{KH}_{2} \mathrm{PO}_{4}\right)$. Polyethylene glycol standards (PEG $20 \mathrm{kDa}, 10 \mathrm{kDa}, 6 \mathrm{kDa}, 4 \mathrm{kDa}, 1.5 \mathrm{kDa}, 600 \mathrm{Da}$ and $200 \mathrm{Da}$ ) from Alfa Aesar were used as apparent molecular weight (AMW) references. The SEC-OCD chromatograms for samples from each ozonation experiment were also processed with Shige software developed by Noda and Ozaki (2005) for 2D correlation analysis - the goal of which was to ascertain potentially small variations of various spectra resulting from external perturbations, e.g., DOM ozonation in this study (supporting information Figure S4).

\subsection{Bromide and bromate Analysis}

Bromide concentrations were determined by means of IC-ICP-MS, using a PerkinElmer Series 200 HPLC coupled with a PerkinElmer SCIEX ELAN DRC-e ICP/MS Spectrometer. These analyses were done in accord with prior investigators (Shi and Adams 2009).

Bromate concentrations were determined by means of ion chromatography with MS/MS detection, using a Shimadzu Prominence LC-20 series HPLC system coupled with an API 4000 QTrap hybrid triple quadrupole/linear ion trap mass spectrometer (AB SCIEX) operating with negative mode electrospray ionization. Separations were performed using an ion exchange column $(2 \times 250 \mathrm{~mm}$ Dionex IonPac AS-16 w/ $2 \times$ $50 \mathrm{~mm}$ AG-16 guard column) under isocratic conditions, with a mobile phase comprising $20 \%$ of a $1 \mathrm{~mol} / \mathrm{L}$ aqueous methylamine solution and $80 \%$ of acetonitrile, at a flow rate of $0.25 \mathrm{~mL} / \mathrm{min}$ and injection volume of $100 \mu \mathrm{L}$. The mass parameters 
used in multiple reaction monitoring mode for $\mathrm{BrO}_{3}{ }^{-}$identification and quantification were $128.9 \rightarrow 113.0$ and $126.9 \rightarrow 110.8$. Method detection and quantification limits for $\mathrm{BrO}_{3}{ }^{-}$were 0.03 and $0.1 \mu \mathrm{g} / \mathrm{L}$, respectively.

\section{Results and discussion}

\subsection{Degradation of chromophores}

Absorbance spectra of water and wastewater ozonated at varying $\mathrm{O}_{3} / \mathrm{DOC}$ ratios normalized by the original samples' absorbance spectra are shown in Figure $\mathbf{1}$ and Figure S2. At all wavelengths $>230 \mathrm{~nm}$, these spectra showed a monotonic decrease of absorbance associated with the increase of ozone dosage. Consistent with previous results (Chon et al. 2015, Gerrity et al. 2012), the normalized absorbance spectra were relatively flat in the wavelength range $>250 \mathrm{~nm}$. The flat region in the normalized absorbance spectra could be separated into sub-ranges below $\sim 350 \mathrm{~nm}$ and above $\sim 370 \mathrm{~nm}$. At low ozone doses $\left(\mathrm{O}_{3} / \mathrm{DOC}<0.4\right)$, the observed variations of the normalized absorbance at $\lambda<350 \mathrm{~nm}$ were less pronounced than those of the relative residual absorbance at $\lambda>370 \mathrm{~nm}$, and such relationships then reversed at the higher $\mathrm{O}_{3} / \mathrm{DOC}$ ratios. This phenomenon indicates that the chromophores comprise at least two kinetically distinct functionalities during ozonation (Nanaboina and Korshin 2010). Due to its relatively high absolute value, the UV absorbance in the range of 250-300 nm presents a more convenient option for online monitoring than absorbance at $\lambda>300 \mathrm{~nm}$.

Figure 2 illustrates that UVA254 and UVA280 represented as a function of 
$\mathrm{O}_{3}$ /DOC ratio or ozonation time exhibit similar changes. With the increase of $\mathrm{O}_{3} / \mathrm{DOC}$ ratio, the UVA indices decreased steeply at low $\mathrm{O}_{3} / \mathrm{DOC}$ ratios $(<0.5 \mathrm{mg}$ $\mathrm{O}_{3} / \mathrm{mg}$ DOC) and then decreased more gradually at higher $\mathrm{O}_{3} / \mathrm{DOC}$ ratios. When presented vs. ozonation time, the normalized residual UVA indices decreased more steeply at the initial ozonation stage $(<40 \mathrm{~s})$ and more gradually for longer ozonation times. This phenomenon could be explained by the contributions of kinetically different groups of chromophores and also changes of the ozone transfer rate which varied as a function of time (Figure S1). The $\mathrm{O}_{3} /$ DOC ratios related to such inflection points were in the range of $0.4-0.6 \mathrm{mg} \mathrm{O} / \mathrm{mg}$ DOC. At these $\mathrm{O}_{3} / \mathrm{DOC}$ ratios, UVA254 and UVA280 were decreased by about $45-60 \%$. Given that the observed changes of the absorbance of ozonated water were similar for the two examined wavelengths, it can be concluded that measurements at $280 \mathrm{~nm}$ - a practically implementable LED emission wavelength feasible for online applications - may represent an excellent alternative to UVA254 measurements in the context of evaluation of ozonation efficiency as well as DBP formation during chlorination (Li et al. 2016a).

\subsection{Degradation of fluorophores}

Representative fluorescence excitation-emission matrixes (EEM) of untreated wastewater and surface water samples are shown in Figure 3. Generally, the fluorescence peaks with $E m<380 \mathrm{~nm}$ are ascribed to protein-like fluorescence while the fluorescence peaks with Em>380 nm are ascribed to humic-like fluorescence associated with fluorophores comprising aromatic rings substituted with various 
electron-donating functional groups (Barsotti et al. 2016, Li et al. 2013, Li et al. 2015).

The examined wastewater samples showed the presence of two protein-like fluorescence peaks $(\mathrm{Em} \sim 350 \mathrm{~nm})$ and two humic-like fluorescence peaks $(\mathrm{Em} \sim 430$ $\mathrm{nm}$ ), while the EEM of Lake Pleasant water was dominated by two humic-like fluorescence peaks $(\mathrm{Em} \sim 450 \mathrm{~nm})$. The comparison of the fluorescence data obtained with the LED sensor and the lab benchtop spectrometer (Table S1) indicates a very good convergence of these results and thus confirms the good sensitivity and accuracy of the LED sensor for use in online monitoring applications. However, the sensitivity of the LED sensor to humic-like fluorescence is much higher than to protein-like fluorescence, mainly due to the fluorescence integration area, the transmittance efficiency of the sensor's bandpass filter, and the response sensitivity of photodiodes to UV light. Due to the relatively weak contribution of protein-like fluorescence in Lake Pleasant samples, measurements of humic-like fluorescence are mainly discussed hereafter.

Figure 4 illustrates the degradation of humic-like fluorophores during ozonation. The humic-like fluorescence decreased very steeply at the initial stage of ozonation time $(<25 \mathrm{~s})$ and then reached to a distinguishable flat region at high ozone time. Like for UVA254 and UVA280, the decrease of humic-like fluorescence as a function of $\mathrm{O}_{3} /$ DOC ratio could also be divided into two stages; however, more than $80 \%$ of the humic-like fluorescence was lost in the initial stage - much higher than for the UVA indices. The $\mathrm{O}_{3} / \mathrm{DOC}$ ratios related to such inflection points between these two stages 
were in the range of 0.3-0.4.

\subsection{Formation of BDOC}

Figure 5a presents the formation of $\mathrm{BDOC}_{\text {rapid }}$ as a function of $\mathrm{O}_{3} / \mathrm{DOC}$ ratio or ozonation time. These data demonstrate that the formation of $\mathrm{BDOC}_{\text {rapid }}$ increased gradually at $\mathrm{O}_{3} / \mathrm{DOC}$ ratios $<0.4$ and while it increased more steeply for $\mathrm{O}_{3} / \mathrm{DOC}$ ratios 0.4-0.7. Above the latter transitional range of $\mathrm{O}_{3} / \mathrm{DOC}$ ratios, $\mathrm{BDOC}_{\text {rapid }}$ formation leveled off with distinguishable plateaus at higher $\mathrm{O}_{3} / \mathrm{DOC}$ ratios, suggesting that the remaining DOM is relatively refractory and requires more $\mathrm{O}_{3}$ to be converted to the biodegradable form. Similar patterns of BDOC formation at low $\mathrm{O}_{3}$ doses were observed in prior studies. For instance, Win et al. (2000) found that the biodegradability of DOM was not appreciably affected by ozonation until a threshold of ozone dose was reached. Liu et al. (2015) reported that there was no significant formation of aldehydes and carboxylic acids that comprise a large part of the assimilable organic carbon (AOC) in ozonated wastewater (DOC $7.8 \mathrm{mg} / \mathrm{L}$ ) with $\mathrm{O}_{3}$ dose less than $2 \mathrm{mg} / \mathrm{L}$. The plateau in $\mathrm{BDOC}_{\text {rapid }}$ formation at higher $\mathrm{O}_{3} / \mathrm{DOC}$ ratios is also consistent with prior observations (Siddiqui et al. 1997, Treguer et al. 2010). When represented as a function of the decrease of UV absorbance and fluorescence (Figure 5b\&c), the $\mathrm{BDOC}_{\text {rapid }}$ concentrations increased slowly in the initial stage and then rose more noticeably. The inflection points in these plots corresponding to the decrease of UVA indices and fluorescence were close to $35-45 \%$, and $75-85 \%$, respectively.

The degradation of DOM during ozonation can occur through either direct 
reaction with $\mathrm{O}_{3}$, or with ${ }^{\circ} \mathrm{OH}$ radical generated during $\mathrm{O}_{3}$ decomposition (von Gunten 2003a, Wert et al. 2009). During the initial ozone demand stage (Figure S3), ozone reacts directly and selectively with electron-rich moieties, e.g., aromatic chromophores or fluorophores (Chon et al. 2015, Wert et al. 2009, Wu et al. 2016), resulting in the rapid decreases of UV absorbance and fluorescence signals (Figure 2 and Figure 4). Prior research based on ozonation experiments (DOC 1.2-1.4 mg/L, $\mathrm{O}_{3}$ $2 \mathrm{mg} / \mathrm{L}$ ) performed with and without ${ }^{\circ} \mathrm{OH}$ scavengers confirmed that direct ozone reactions are mainly responsible for the formation of small organic compounds contributing to AOC during the initial ozone demand stage (Hammes et al. 2006). However, such AOC molecules might not be produced substantially at very low ozone dose (Liu et al. 2015). In the present work, it is possible that the initial selective attacks of $\mathrm{O}_{3}$ on electron-rich moieties were not sufficient to break down the large MW DOM fractions into small molecules associated with AOC, leading to the apparent lag in formation of $\mathrm{BDOC}_{\text {rapid }}$ at $\mathrm{O}_{3} / \mathrm{DOC}$ ratios $<0.4$ The presence of small quantities of inorganic constituents that might exert rapid $\mathrm{O}_{3}$ demand at low $\mathrm{O}_{3}$ doses (e.g., $\mathrm{NO}_{2}^{-}$) also cannot be ruled out. With greater $\mathrm{O}_{3}$ doses, increasing exposure to $\mathrm{O}_{3}$ and ${ }^{\circ} \mathrm{OH}$ may have led to more extensive breakdown of aromatic structures and other electron-rich targets through direct reactions with $\mathrm{O}_{3}$ and indirect reactions involving the much less selective ${ }^{\circ} \mathrm{OH}$ (Legrini et al. 1993, von Gunten 2003a). At $\mathrm{O}_{3} / \mathrm{DOC}$ ratios above $0.4-0.7$, the observed decrease in formation of $\mathrm{BDOC}_{\text {rapid }}$ may be attributable to accumulation of more $\mathrm{O}_{3^{-}}$and ${ }^{\circ} \mathrm{OH}$-recalcitrant products (e.g., acetic and oxalic acids) (Hammes et al. 2006, Ramseier and Gunten 2009). The synergistic 
effect of $\mathrm{O}_{3}$ and ${ }^{\circ} \mathrm{OH}$ radical contributed to the sufficient decomposition of large MW DOM and the prominent formation of AOCs.

\subsection{Evolution of DOM molecular weight during ozonation}

Figure 6 shows the evolution of SEC-OCD chromatograms of WWTP effluent and Lake Pleasant water during ozonation. In SEC experiments, DOM fractions with higher apparent MW have lower elution times (Figure S4). Using peak assignments introduced in prior research (Huber et al. 2011) to denote major features observed in the data shown in Figure 6, both WWTP effluent and Lake Pleasant water had a biopolymer-like peak of large AMW (peak a1 and peak b1, 20-30 min, AMW > 20 $\mathrm{kDa}$ ). The WWTP effluent exhibited several peaks in the medium AMW range (peak a2, humic-like peak, 30-36 min, AMW of 14-5.5 $\mathrm{kDa}$; peak a3, peak of building blocks, 36-40 min, AMW of 5.5-3 kDa) and two well-resolved peaks located at lower AMW values (peak a4, peak of low MW acids, 40-48 min, AMW of 3-0.8 kDa; peak a5, peak of low MW neutrals, 50-60 min, AMW < 800 Da). SEC-OCD data for Lake Pleasant water exhibited a prominent peak b2 (humic-like peak, 28-36 min, AMW of 20-5.5 kDa) with a shoulder b3 (building blocks, 36-40 min, AMW of 5.5-3 kDa). These peaks located in the range of medium AMW typically attributed to humic substances were responsible for a large portion of DOC in untreated Lake Pleasant water. The SEC-OCD of Lake Pleasant water also had two weaker peaks located in the range of small AMW (peak b4 and peak b5), which are designated as low MW acids and neutrals. 
in Figure 6. It is also visualized using 2D synchronous correlation contours (Figure S5). At increasing ozone dosages, the large MW biopolymer-like peaks (a1 and b1) and medium MW humic-like peaks ( $\mathrm{a} 2$ and b2) decreased while the concentration of building blocks and low MW acids and neutrals increased, suggesting that the larger ozonation. The newly formed medium building blocks and small MW DOM species were easily biodegraded and mainly contributed to the $\mathrm{BDOC}_{\text {rapid }}$ (Figure S6). The SEC-OCD results also confirmed that the decomposition of biopolymer-like or humic-like peaks was not prominent $(<20 \%)$ during the initial ozonation stage, despite the substantial losses of UVA and fluorescence (Figure S7).

\subsection{Formation of bromate}

Figures 7a-b depict bromate yields (expressed as mol ratios of $\mathrm{Br}$ associated with $\mathrm{BrO}_{3}{ }^{-}$to initial $\mathrm{Br}^{-}\left(\left[\mathrm{BrO}_{3}{ }^{-}\right] /\left[\mathrm{Br}^{-}\right]\right.$, in $\left.\% \mathrm{~mol} / \mathrm{mol}\right)$ plotted as a function of $\mathrm{O}_{3} / \mathrm{DOC}$ ratio or ozonation time. The observed relationships exhibit the presence of two phases of bromate formation, as marked by the dash line. During the initial phase $\left(\mathrm{O}_{3} / \mathrm{DOC}\right.$ ratios $<0.4$ or ozonation time $<25 \mathrm{~s})$, bromate yields were low $\left(\left[\mathrm{BrO}_{3}{ }^{-}\right] /\left[\mathrm{Br}^{-}\right]<2 \%\right)$ and effects of initial $\mathrm{Br}^{-}$concentrations on this phase were minor. This is in agreement with the data of previous studies (Chon et al. 2015, Soltermann et al. 2016), which observed a negligible bromate yield $(\leq 3 \%)$ for $\mathrm{O}_{3} / \mathrm{DOC}$ ratios $<0.4-0.6 \mathrm{mg} \mathrm{O} / \mathrm{mg}$ DOC. 

of bromate, which is generated via a complex mechanism involving ozone and hydroxyl radical (Fischbacher et al. 2015, von Gunten and Oliveras 1998). During the initial phase of bromate formation $\left(\mathrm{O}_{3} / \mathrm{DOC}\right.$ ratios $<0.4$, ozonation time $\left.<25 \mathrm{~s}\right), \mathrm{O}_{3}$ is rapidly consumed by electron-rich moieties (Buffle et al. 2006, Lee et al. 2013) whose consumption is consistent with the rapid decrease of humic-like fluorescence (Figure 
formation across different water matrixes.

Figures 7c-d present the normalized bromate yields $\left(\left[\mathrm{BrO}_{3}{ }^{-}\right] /\left[\mathrm{Br}{ }^{-}\right], \mathrm{mol} / \mathrm{mol}\right)$ as a function of relative changes in the spectroscopic parameters UVA254, UVA280 and humic-like fluorescence. In agreement with one previous study (Chon et al. 2015), the plots of bromate yields vs. spectroscopic indicators overlapped for all data sets obtained in the ozonation experiments, although the DOM properties and initial $\mathrm{Br}^{-}$ concentrations were different. Similarly to the observations discussed above, changes in the bromate yields could be further divided into two stages characterized by significantly different slopes vs. corresponding spectroscopic index. The inflection points related to the appreciable formation of $\mathrm{BrO}_{3}{ }^{-}$were in the range of $45-55 \%$, 50-60\% and 86-92\% losses of UVA254, UVA280, and humic-like fluorescence, respectively. Unlike $\mathrm{O}_{3} / \mathrm{DOC}$ ratios, the plots of $\left[\mathrm{BrO}_{3}^{-}\right] /\left[\mathrm{Br}^{-}\right]$as a function of the spectroscopic indicators in the second phase had relatively small differences for the data obtained for Lake Pleasant and WWTP effluent samples, suggesting that the spectroscopic indices may be more suitable as a surrogate parameter for bromate formation in waters of varying composition.

With respect to the US EPA's MCL for $\mathrm{BrO}_{3}{ }^{-}$in drinking water of $10 \mu \mathrm{g} / \mathrm{L}$, the breakthrough points related to removals of UVA254, UVA280 and decrease of humic-like fluorescence were in the range of $45-55 \%, 52-57 \%$, and $86-90 \%$, respectively (Figure 8). In contrast to the observations made for $\left[\mathrm{BrO}_{3}{ }^{-}\right] /\left[\mathrm{Br}^{-}\right]$molar yields (Figure 7), plots of $\mathrm{BrO}_{3}{ }^{-}$vs UVA254 and $\mathrm{BrO}_{3}{ }^{-}$vs UVA280 diverged into distinct groups of data for WWTP effluents and Lake Pleasant. Such divergences 
were presumably due to differences in initial $\mathrm{Br}^{-}$concentrations in the various matrixes, since $\mathrm{BrO}_{3}{ }^{-}$yields were not normalized to initial $\mathrm{Br}^{-}$levels in these plots. Additionally, chromophores in Lake Pleasant water appeared to be much more susceptible to the oxidation at higher $\mathrm{O}_{3}$ exposures than chromophores in WWTP effluents (Figure 2). However, no significant divergences between the data for dissimilar water matrixes were observed in plots of $\mathrm{BrO}_{3}{ }^{-}$vs humic fluorescence. In comparison to the $\sim 25 \%$ variation amongst UVA indices in the various matrixes at higher $\mathrm{O}_{3}$ exposures, further decreases of humic-like fluorescence were limited in a narrow range from $90 \%$ to $100 \%$. The association of this narrow range of changes of humic-like fluorescence with the generation of bromate is likely to have largely eliminated any divergence attributable to differences in initial $\mathrm{Br}^{-}$concentration. A previous study also reported a sole correlation between a fluorescence index and several chlorinated DBPs regardless of the water source and treatment, while the differential absorbance correlations could be interfered by many species (Roccaro et al. 2009). These results showed that fluorescence indices may have more advantages than absorbance indices in actual water systems.

The plots of $\mathrm{BrO}_{3}{ }^{-}$concentration $(\mu \mathrm{g} / \mathrm{L})$ versus decrease of humic fluorescence (HS, in \%) were fitted by MATLAB software (Figure S9), and an empirical equation applicable to the ranges of 6-7 $\mathrm{mg} / \mathrm{L}$ DOC and $100-500 \mu \mathrm{g} / \mathrm{L} \mathrm{Br}^{-}$was obtained, as presented below:

$$
\mathrm{BrO}_{3}^{-}(\mu \mathrm{g} / \mathrm{L})=7.64 * 10^{-9} * e^{0.237 * H S(\%)}, R^{2}=0.962
$$


440 fluorescence of ozonated water are highly suitable for the estimation of bromate

441 formation in dissimilar water matrixes. The results in Figure S10 further indicate that

442 DOC concentration has relatively little effect on the relationships between bromate

443 formation and humic-like fluorescence. However, the robustness of such relationships

444 still needs to be explored in the future; for example, with respect to the effects of $\mathrm{pH}$,

445 temperature, DOC and $\mathrm{NH}_{4}{ }^{+}$concentrations.

In the context of optimization of ozone dosage, the typical goal is to maximize the effect of oxidation while simultaneously minimizing the formation of undesired byproducts. Gerrity et al. (2012) previously reported that $\sim 50 \%$ reduction of UVA254 or $\sim 90 \%$ decrease of total fluorescence were required to reach acceptable levels of pathogen inactivation and sufficient elimination of many micropollutants. The present work supports these findings and demonstrates possible approaches for assessing the potential formation of $\mathrm{BDOC}$ and bromate during water and wastewater ozonation, especially for water having bromide concentrations above $50 \mu \mathrm{g} / \mathrm{L}$.

\section{Conclusions}

- When represented as a function of changes of spectroscopic indicators such as UVA254, UVA280, and humic-like fluorescence, BDOC concentrations initially increased slowly and then rose more noticeably. The inflection points indicative of BDOC formation threshold were located in the range of $35-45 \%$ loss of UVA254 or UVA280 and 75-85\% loss of humic-like fluorescence. 
- SEC-OCD data showed that large biopolymer molecules in WWTP effluent

461 (apparent MW>20 kDa) and medium-AMW humic substances in Lake Pleasant

462 surface water (AMW 5.5-20 kDa) were transformed into medium-AMW building

463 blocks and small AMW species associated with BDOC.

464

- When represented as a function of spectroscopic indicators, the inflection points that corresponded to the onset of bromate formation were approximately $45-55 \%$, 50-60\% and 86-92\% for decreases in UVA254, UVA280 and humic fluorescence, respectively.

- An empirical equation modeling the relationship between bromate concentrations (expressed in $\mu \mathrm{g} / \mathrm{L}$ ) and concomitant decreases of humic-like fluorescence (\%) was established based on the data generated for wastewater effluent and surface water that had 100 to $500 \mu \mathrm{g} / \mathrm{L} \mathrm{Br}^{-}$.

- The results suggest that measurements of UVA280 and humic-like fluorescence complement conventional UVA254 measurements, especially in the context of assessing the formation of BDOC and bromate. The use of these spectroscopic parameters is expected to be enhanced by the recent development of online/portable spectrometers that use LEDs as a light source.

\section{Acknowledgement}

We thank the generous support from National Key R\&D Program (No. 2016YFE0112300), National Science Foundation of China (No. 51438008) and

MADFORWATER (No. 688320) for the development of LED UV fluorescence 
481 sensor. We also acknowledge the support for Tessora Young from her NSF graduate 482 research fellowship. Wentao Li thanks the scholarship from the China Scholarship 483 Council (No. 201506190059) and Shanghai Tongji GaoTingyao Environmental 484 Science \& Technology Development Foundation (STGEF).

\section{Appendix A. Supplementary data}

486 Supplementary data related to this article can be found in Supporting Information. 


\section{References}

Bader, H. and Hoigné, J., 1981. Determination of ozone in water by the indigo method. Water Research 15 (4), 449-456.

Barsotti, F., Ghigo, G. and Vione, D., 2016. Computational assessment of the fluorescence emission of phenol oligomers: A possible insight into the fluorescence properties of humic-like substances (HULIS). Journal of Photochemistry and Photobiology a-Chemistry 315, 87-93.

Black, K.E. and Berube, P.R., 2014. Rate and extent NOM removal during oxidation and biofiltration. Water Research 52, 40-50.

Bridgeman, J., Baker, A., Brown, D. and Boxall, J.B., 2015. Portable LED fluorescence instrumentation for the rapid assessment of potable water quality. Science of The Total Environment 524-525, 338-346.

Buffle, M.-O., Schumacher, J., Salhi, E., Jekel, M. and von Gunten, U., 2006. Measurement of the initial phase of ozone decomposition in water and wastewater by means of a continuous quench-flow system: Application to disinfection and pharmaceutical oxidation. Water Research 40 (9), 1884-1894.

Butler, R., Godley, A., Lytton, L. and Cartmell, E., 2005. Bromate environmental contamination: Review of impact and possible treatment. Critical Reviews in Environmental Science and Technology 35 (3), 193-217.

Chin, Y.-P., Aiken, G. and O'Loughlin, E., 1994. Molecular Weight, Polydispersity, and Spectroscopic Properties of Aquatic Humic Substances. Environmental Science \& Technology 28 (11), 1853-1858. 
50Q hhiou, C.F., Marinas, B.J. and Adams, J.Q., 1995. Modified indigo method for 510 gaseous and aqueous ozone analyses. Ozone-Science \& Engineering 17 (3), $511 \quad 329-344$.

51Chon, K., Salhi, E. and von Gunten, U., 2015. Combination of UV absorbance and 513 electron donating capacity to assess degradation of micropollutants and 514 formation of bromate during ozonation of wastewater effluents. Water Research $515 \quad 81,388-397$.

51Ђodd, M.C., Kohler, H.P.E. and von Gunten, U., 2009. Oxidation of Antibacterial 517 Compounds by Ozone and Hydroxyl Radical: Elimination of Biological Activity 518 during Aqueous Ozonation Processes. Environmental Science \& Technology 43 519 (7), 2498-2504.

52Escobar, I.C. and Randall, A.A., 2001. Assimilable organic carbon (AOC) and 521 biodegradable dissolved organic carbon (BDOC): Complementary measurements. $522 \quad$ Water Research 35 (18), 4444-4454.

52Bimmen, R.L., Cory, R.M., Chin, Y.-P., Trouts, T.D. and McKnight, D.M., 2007. 524 Probing the oxidation-reduction properties of terrestrially and microbially 525 derived dissolved organic matter. Geochimica et Cosmochimica Acta 71 (12), $526 \quad 3003-3015$.

52Fischbacher, A., Loeppenberg, K., von Sonntag, C. and Schmidt, T.C., 2015. A New 528 Reaction Pathway for Bromite to Bromate in the Ozonation of Bromide. 529 Environmental Science \& Technology 49 (19), 11714-11720.

53Grerrity, D., Gamage, S., Jones, D., Korshin, G.V., Lee, Y., Pisarenko, A., Trenholm, 

surrogate correlation models to predict trace organic contaminant oxidation and microbial inactivation during ozonation. Water Research 46 (19), 6257-6272.

Hammes, F., Salhi, E., Koster, O., Kaiser, H.P., Egli, T. and von Gunten, U., 2006. 
55\#ee, C.O., Howe, K.J. and Thomson, B.M., 2012. Ozone and biofiltration as an 555 alternative to reverse osmosis for removing PPCPs and micropollutants from 556 treated wastewater. Water Research 46 (4), 1005-1014.

55Lee, Y., Gerrity, D., Lee, M., Bogeat, A.E., Salhi, E., Gamage, S., Trenholm, R.A., 558 Wert, E.C., Snyder, S.A. and von Gunten, U., 2013. Prediction of Micropollutant 559 Elimination during Ozonation of Municipal Wastewater Effluents: Use of 560 Kinetic and Water Specific Information. Environmental Science \& Technology $56147(11), 5872-5881$.

56Regrini, O., Oliveros, E. and Braun, A.M., 1993. Photochemical processes for water 563 treatment. Chemical Reviews 93 (2), 671-698.

56甘i, W.-T., Jin, J., Li, Q., Wu, C.-F., Lu, H., Zhou, Q. and Li, A.-M., 2016 a. 565 Developing LED UV fluorescence sensors for online monitoring DOM and 566 predicting DBPs formation potential during water treatment. Water Research 93, $567 \quad 1-9$.

56Bi, W.-T., Xu, Z.-X., Li, A.-M., Wu, W., Zhou, Q. and Wang, J.-N., 2013. 569 HPLC/HPSEC-FLD with multi-excitation/emission scan for EEM interpretation 570 and dissolved organic matter analysis. Water Research 47 (3), 1246-1256.

57Li, W., Nanaboina, V., Chen, F. and Korshin, G.V., 2016b. Removal of polycyclic 572 synthetic musks and antineoplastic drugs in ozonated wastewater: Quantitation 573 based on the data of differential spectroscopy. Journal of Hazardous Materials $574 \quad 304,242-250$. 
Li, W., Xu, Z., Wu, Q., Li, Y., Shuang, C. and Li, A., 2015. Characterization of fluorescent-dissolved organic matter and identification of specific fluorophores in textile effluents. Environmental Science and Pollution Research 22 (6), 4183-4189.

Liu, C., Nanaboina, V. and Korshin, G., 2012a. Spectroscopic study of the degradation of antibiotics and the generation of representative EfOM oxidation products in ozonated wastewater. Chemosphere 86 (8), 774-782.

Liu, C., Nanaboina, V., Korshin, G.V. and Jiang, W., 2012b. Spectroscopic study of degradation products of ciprofloxacin, norfloxacin and lomefloxacin formed in ozonated wastewater. Water Research 46 (16), 5235-5246.

Liu, C., Tang, X., Kim, J. and Korshin, G.V., 2015. Formation of aldehydes and carboxylic acids in ozonated surface water and wastewater: A clear relationship with fluorescence changes. Chemosphere 125, 182-190.

Nakada, N., Shinohara, H., Murata, A., Kiri, K., Managaki, S., Sato, N. and Takada, H., 2007. Removal of selected pharmaceuticals and personal care products (PPCPs) and endocrine-disrupting chemicals (EDCs) during sand filtration and ozonation at a municipal sewage treatment plant. Water Research 41 (19), 4373-4382.

Nanaboina, V. and Korshin, G.V., 2010. Evolution of Absorbance Spectra of Ozonated Wastewater and Its Relationship with the Degradation of Trace-Level Organic Species. Environmental Science \& Technology 44 (16), 6130-6137.

Nie, Y., Hu, C., Li, N., Yang, L. and Qu, J., 2014. Inhibition of bromate formation by 
59Nishijima, W., Fahmi, Mukaidani, T. and Okada, M., 2003. DOC removal by 600 multi-stage ozonation-biological treatment. Water Research 37 (1), 150-154.

60Noda, I. and Ozaki, Y. (2005) Two-dimensional correlation spectroscopy: 602 applications in vibrational and optical spectroscopy, John Wiley \& Sons.

60Beter, A. and von Gunten, U., 2007. Oxidation kinetics of selected taste and odor 604 compounds during ozonation of drinking water. Environmental Science \& 605 Technology $41(2), 626-631$.

60Ramseier, M.K. and Gunten, U.v., 2009. Mechanisms of Phenol Ozonation-Kinetics 607 of Formation of Primary and Secondary Reaction Products. Ozone: Science \& 608 Engineering $31(3), 201-215$.

60Reungoat, J., Escher, B.I., Macova, M., Argaud, F.X., Gernjak, W. and Keller, J., 610 2012. Ozonation and biological activated carbon filtration of wastewater 611 treatment plant effluents. Water Research 46 (3), 863-872.

61Roccaro, P., Vagliasindi, F.G.A. and Korshin, G.V., 2009. Changes in NOM 613 Fluorescence Caused by Chlorination and their Associations with Disinfection 614 by-Products Formation. Environmental Science \& Technology 43 (3), 724-729. 61Shi, H. and Adams, C., 2009. Rapid IC-ICP/MS method for simultaneous analysis of 616 iodoacetic acids, bromoacetic acids, bromate, and other related halogenated 617 compounds in water. Talanta $79(2), 523-527$.

618iddiqui, M.S., Amy, G.L. and Murphy, B.D., 1997. Ozone enhanced removal of 

natural organic matter from drinking water sources. Water Research 31 (12), 3098-3106.

Soltermann, F., Abegglen, C., Götz, C. and von Gunten, U., 2016. Bromide Sources and Loads in Swiss Surface Waters and Their Relevance for Bromate Formation during Wastewater Ozonation. Environmental Science \& Technology 50 (18), 9825-9834.

Tedetti, M., Joffre, P. and Goutx, M., 2013. Development of a field-portable fluorometer based on deep ultraviolet LEDs for the detection of phenanthreneand tryptophan-like compounds in natural waters. Sensors and Actuators B-Chemical 182, 416-423.

Treguer, R., Tatin, R., Couvert, A., Wolbert, D. and Tazi-Pain, A., 2010. Ozonation effect on natural organic matter adsorption and biodegradation - Application to a membrane bioreactor containing activated carbon for drinking water production. Water Research 44 (3), 781-788.

von Gunten, U., 2003a. Ozonation of drinking water: Part I. Oxidation kinetics and product formation. Water Research 37 (7), 1443-1467.

von Gunten, U., 2003b. Ozonation of drinking water: Part II. Disinfection and by-product formation in presence of bromide, iodide or chlorine. Water Research 37 (7), 1469-1487.

von Gunten, U. and Oliveras, Y., 1998. Advanced Oxidation of Bromide-Containing Waters: Bromate Formation Mechanisms. Environmental Science \& Technology 32 (1), 63-70. 
64Wert, E.C., Rosario-Ortiz, F.L., Drury, D.D. and Snyder, S.A., 2007. Formation of 642 oxidation byproducts from ozonation of wastewater. Water Research 41 (7), $643 \quad 1481-1490$.

64Wert, E.C., Rosario-Ortiz, F.L. and Snyder, S.A., 2009. Using Ultraviolet Absorbance 645 and Color To Assess Pharmaceutical Oxidation during Ozonation of Wastewater. 646 Environmental Science \& Technology 43 (13), 4858-4863.

64Wu, Q., Li, W.T., Yu, W.H., Li, Y. and Li, A.M., 2016. Removal of fluorescent 648 dissolved organic matter in biologically treated textile wastewater by 649 ozonation-biological aerated filter. Journal of the Taiwan Institute of Chemical 650 Engineers 59, 359-364.

65Zimmermann, S.G., Wittenwiler, M., Hollender, J., Krauss, M., Ort, C., Siegrist, H. 652 and von Gunten, U., 2011. Kinetic assessment and modeling of an ozonation step 653 for full-scale municipal wastewater treatment: Micropollutant oxidation, 654 by-product formation and disinfection. Water Research 45 (2), 605-617. 655 
Table 1. Basic characteristics of water matrixes

\begin{tabular}{|c|c|c|c|}
\hline Parameters & WWTP-I & WWTP-II & Lake Pleasant \\
\hline $\mathrm{pH}$ & 6.92 & 6.95 & $7.48^{\mathrm{a}}$ \\
\hline DOC (mg/L) & 5.82 & 6.93 & 14.87 \\
\hline UV254 $\left(\mathrm{cm}^{-1}\right)$ & 0.130 & 0.139 & 0.727 \\
\hline $\mathrm{UV} 280\left(\mathrm{~cm}^{-1}\right)$ & 0.100 & 0.108 & 0.545 \\
\hline Conductivity (us/cm) & 480 & 652 & 314 \\
\hline $\mathrm{Br}^{-}(\mu \mathrm{g} / \mathrm{L})^{\mathrm{b}}$ & 267.8 & 201.5 & 36.7 \\
\hline \multicolumn{4}{|c|}{$\begin{array}{l}\text { a The } \mathrm{pH} \text { values of } 2.5 \text { times diluted lake Pleasant water were about } 7 \text {. } \\
\text { The values listed here are the native background } \mathrm{Br}^{-} \text {concentrations for each } \\
\text { water matrix. Initial } \mathrm{Br}^{-} \text {concentrations during ozonation batch experiments, using } \\
\text { samples of each water matrix fortified with additional bromide, were as follows: } \\
322.9 \mu \mathrm{g} / \mathrm{L} \text { for WWTP-A, } 373.8 \mu \mathrm{g} / \mathrm{L} \text { for WWTP-B, } 491.6 \mu \mathrm{g} / \mathrm{L} \text { for WWTP-C, } \\
301.5 \mu \mathrm{g} / \mathrm{L} \text { for WWTP-D, and } 116.1 \mu \mathrm{g} / \mathrm{L} \text { for LP. }\end{array}$} \\
\hline
\end{tabular}


658 Figure 1. Changes in the absorbance spectra of WWTP effluent as a function of 659 $\mathrm{O}_{3} / \mathrm{DOC}$ ratio normalized by the absorbance prior to treatment Figure 2. Decreases of the normalized residual UVA indices as a function of $\mathrm{O}_{3} / \mathrm{DOC}$ 661 ratio (or ozonation time - inserts): (a) UVA254 and (b) UVA280

Figure 3. EEM spectra of (a) WWTP-I, (b) WWTP-II, and (c) LP. The circles on the 663 left of each graph represent protein-like fluorescence that the LED sensor measures, 664 while the circles on the right of each graph represent humic-like fluorescence that the

665

666

LED sensor measures.

Figure 4. Decrease of the normalized humic-like fluorescence $\left(\mathrm{H} / \mathrm{H}_{0}\right)$ as a function of $\mathrm{O}_{3} / \mathrm{DOC}$ ratio or ozonation time (insert) in different ozonation experiments

Figure 5. Formation of $\mathrm{BDOC}_{\text {rapid }}$ as a function of (a) $\mathrm{O}_{3} / \mathrm{DOC}$ ratio or ozonation time (insert), (b) decrease of UVA254 or UVA280 (insert) and (c) decrease of LED humic-like fluorescence

Figure 6. Evolution of SEC-OCD chromatograms of the ozonated wastewater and surface water as a function of $\mathrm{O}_{3} /$ DOC ratio : (a) WWTP-I effluent (WWTP-A) and (b) Lake Pleasant water (LP).

Figure 7. Bromate formation yields $\left(\left[\mathrm{BrO}_{3}{ }^{-}\right] /\left[\mathrm{Br}^{-}\right], \mathrm{mol} / \mathrm{mol}\right.$ in $\left.\%\right)$ represented as a function of (a) $\mathrm{O}_{3} / \mathrm{DOC}$ ratio, (b) ozonation time, (c) decrease of UVA254 or UVA280 (insert) and (d) decrease of LED humic-like fluorescence.

Figure 8. Bromate formation $(\mu \mathrm{g} / \mathrm{L})$ as a function of decreases of spectral indicators: (a) UVA254 or UVA280 (insert) and (b) LED humic-like fluorescence 


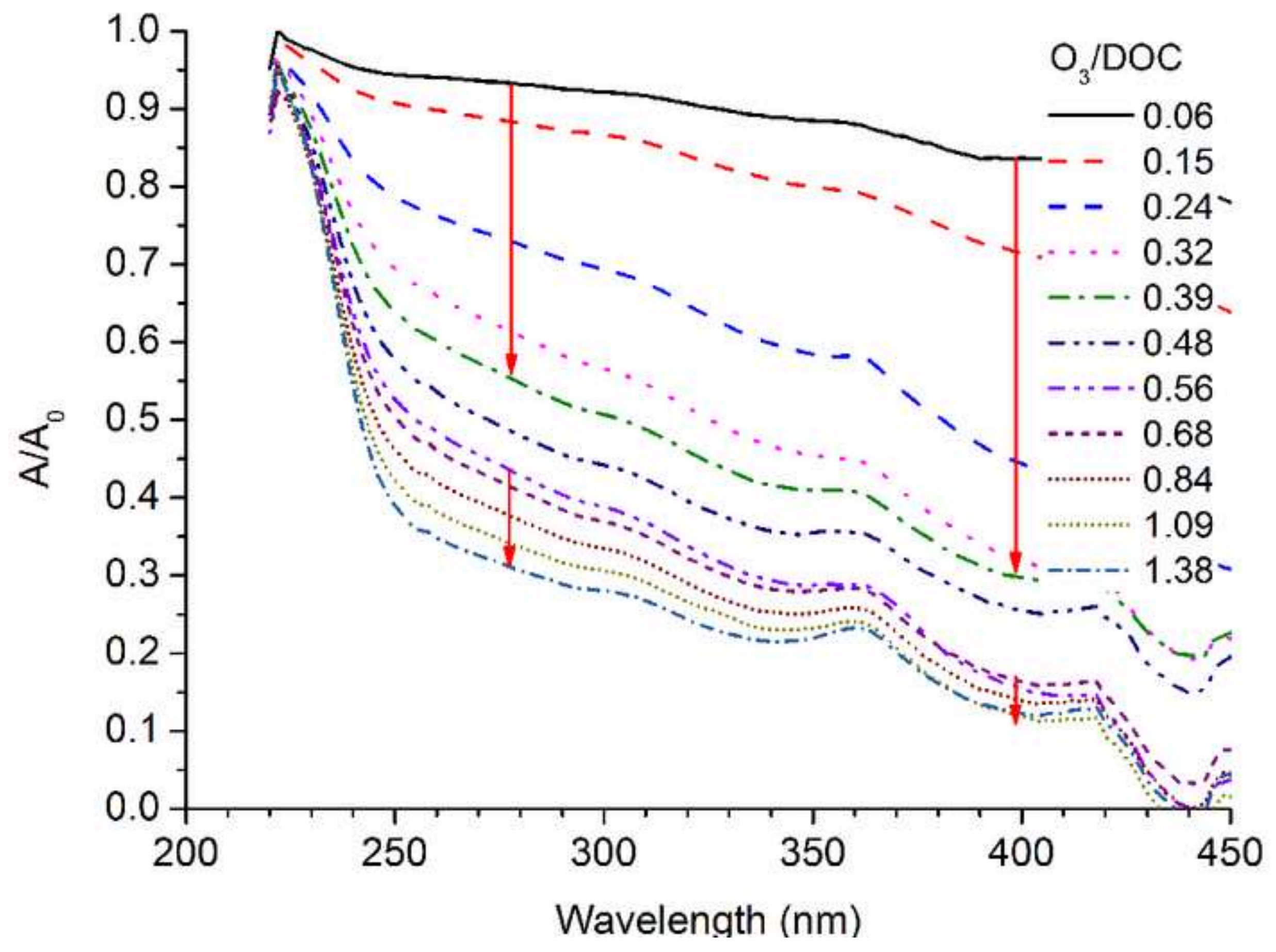



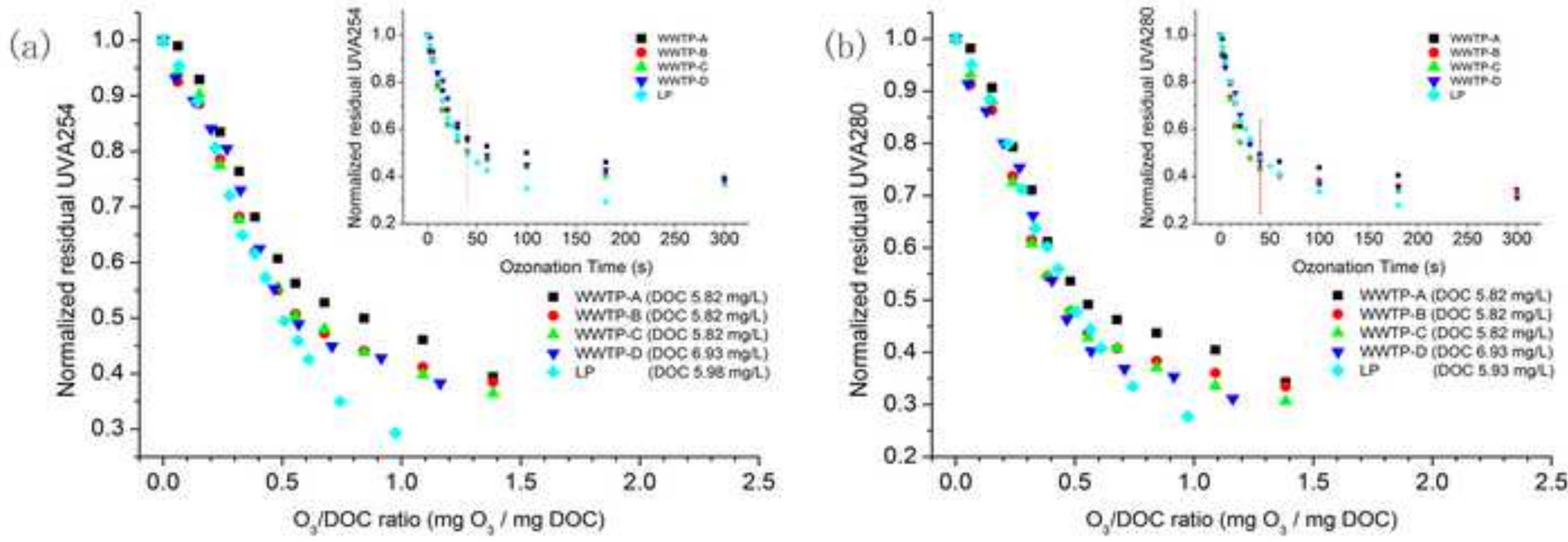
(a)

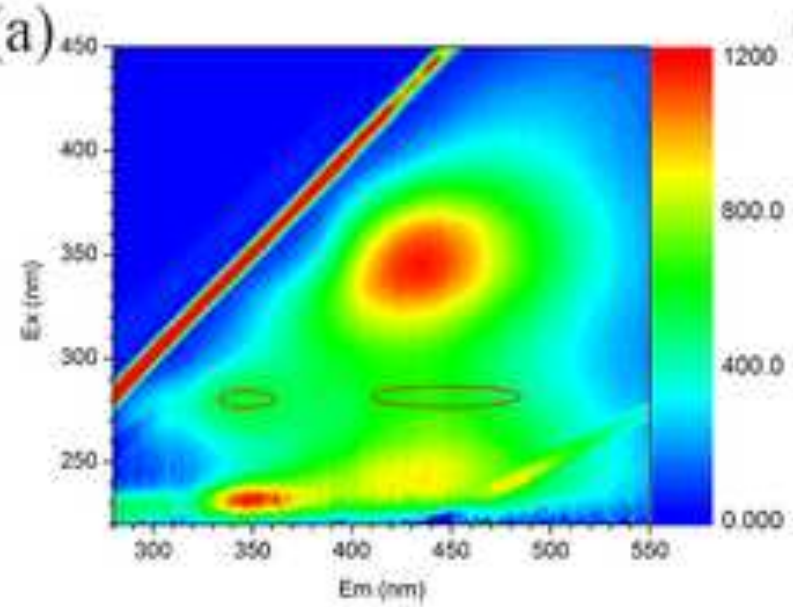

(b)

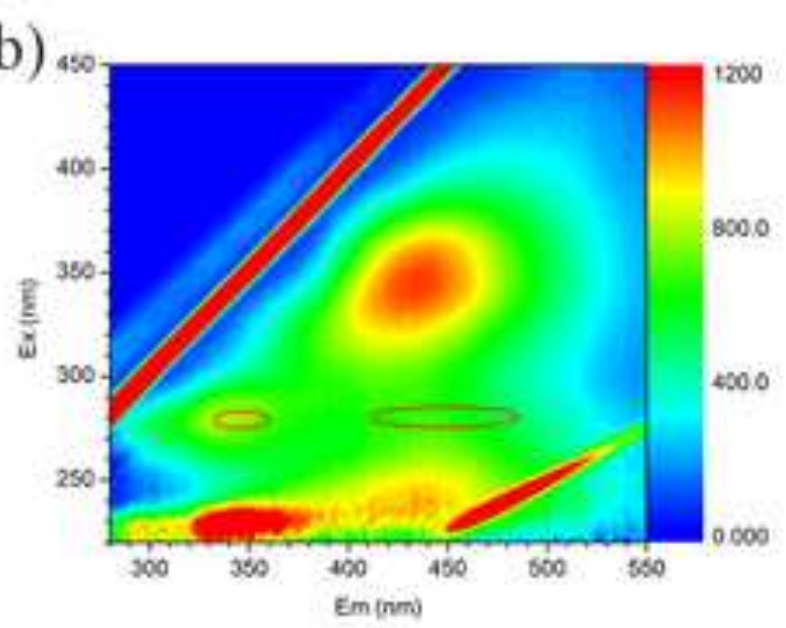

(c)

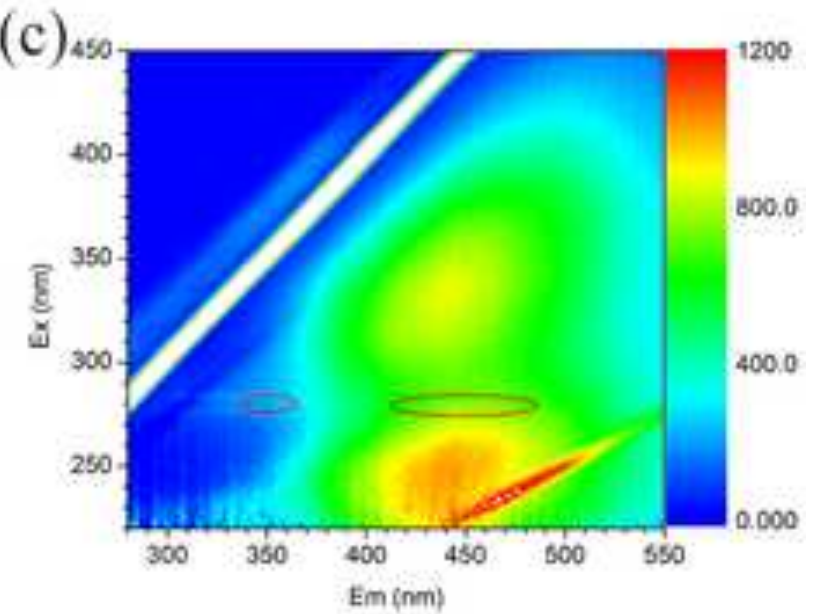

.000

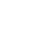




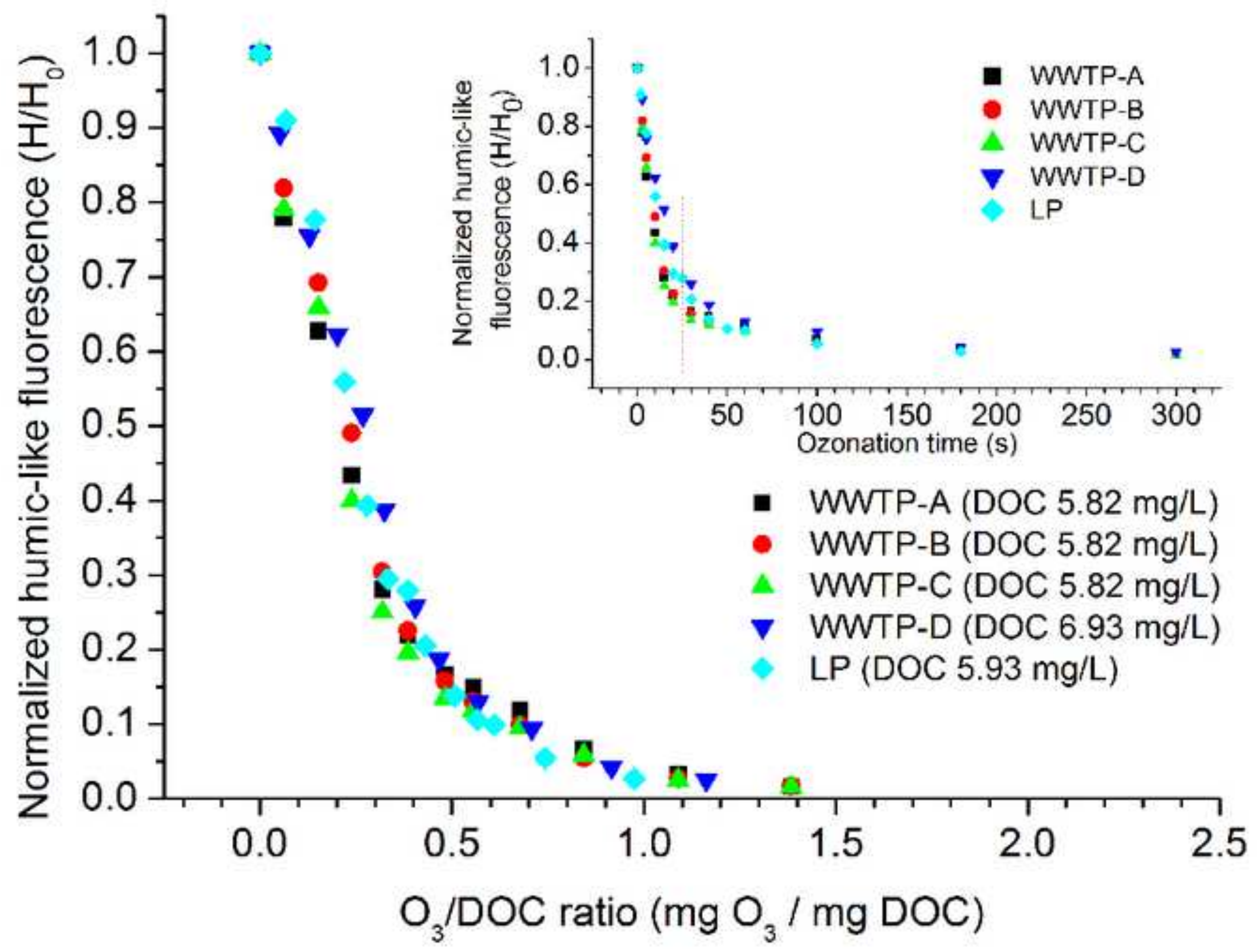



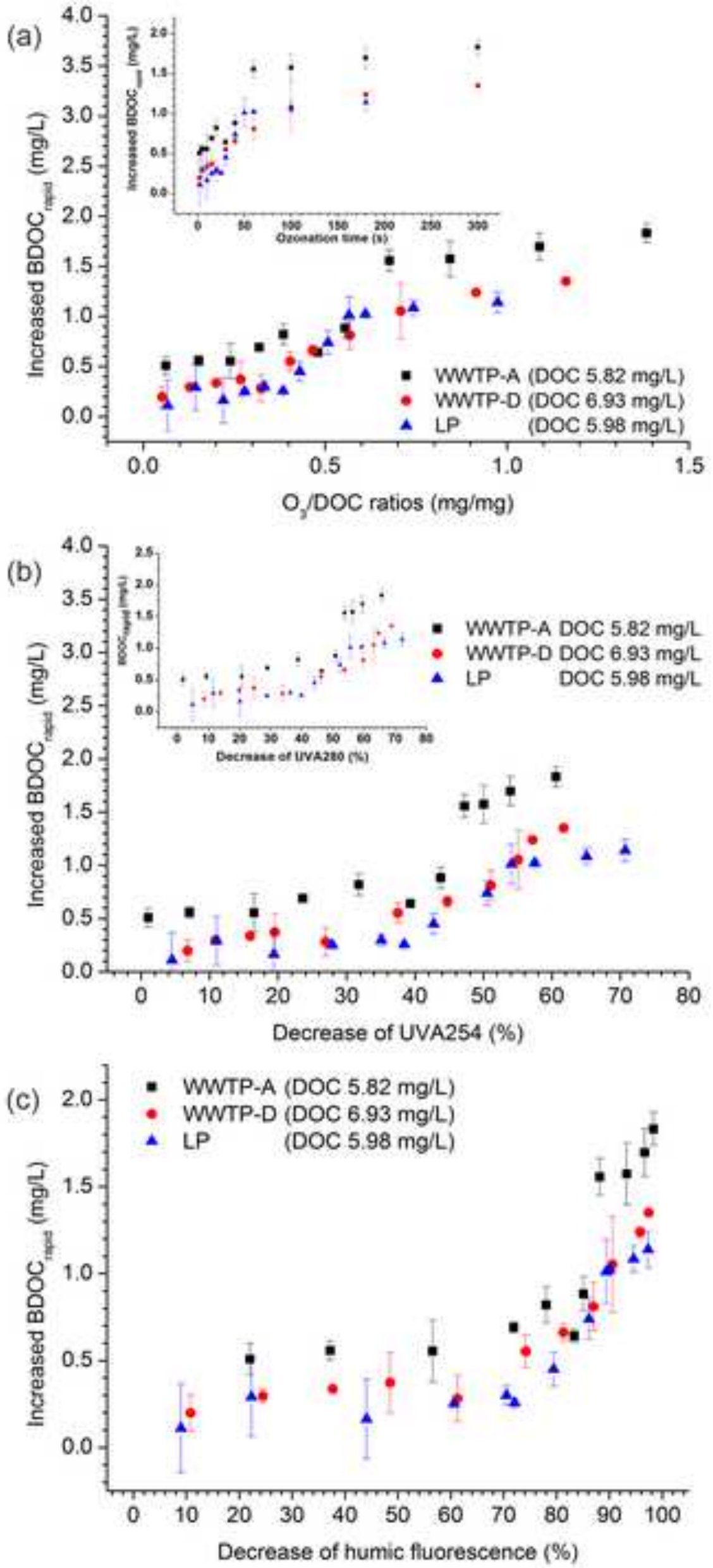

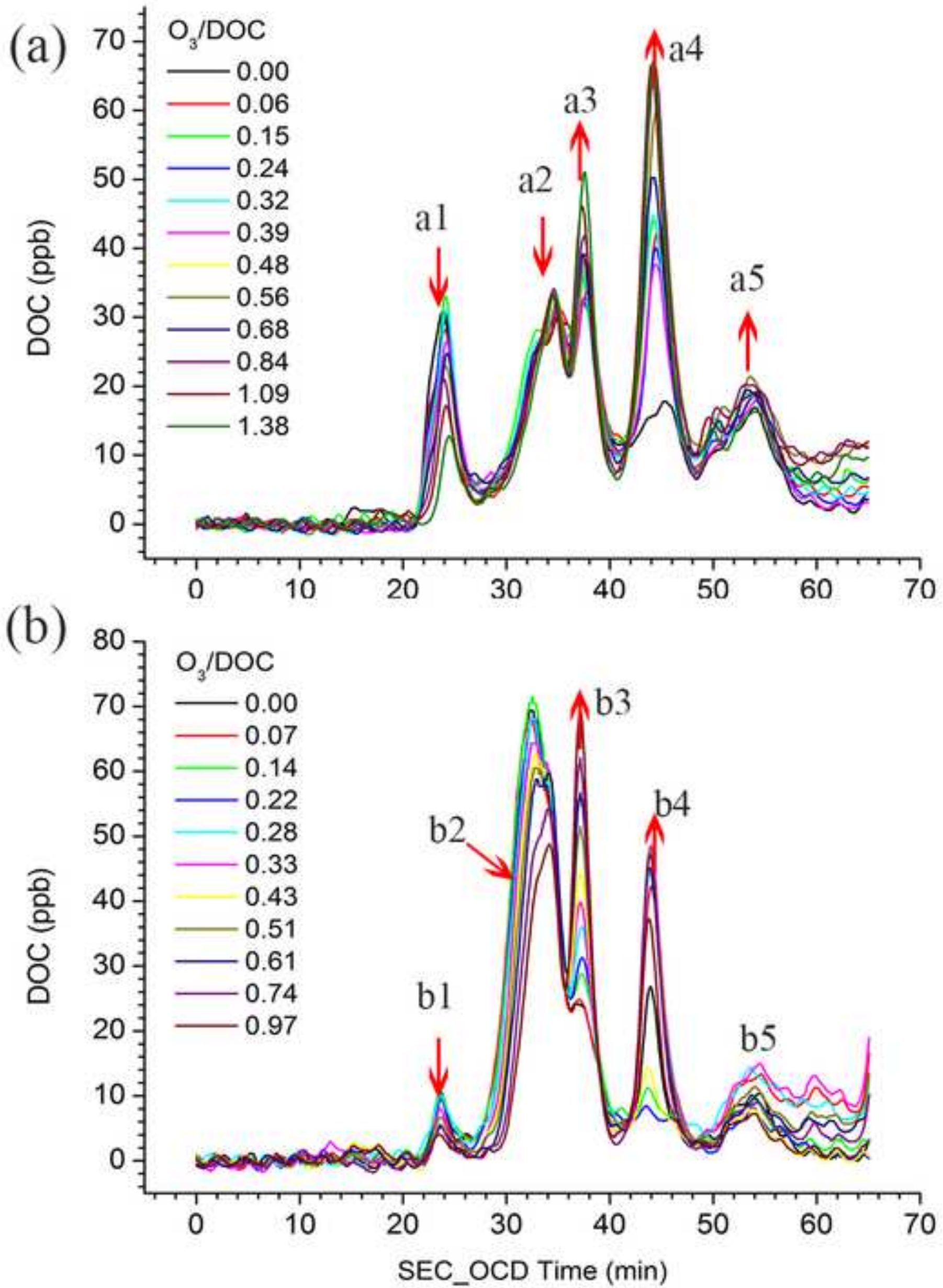

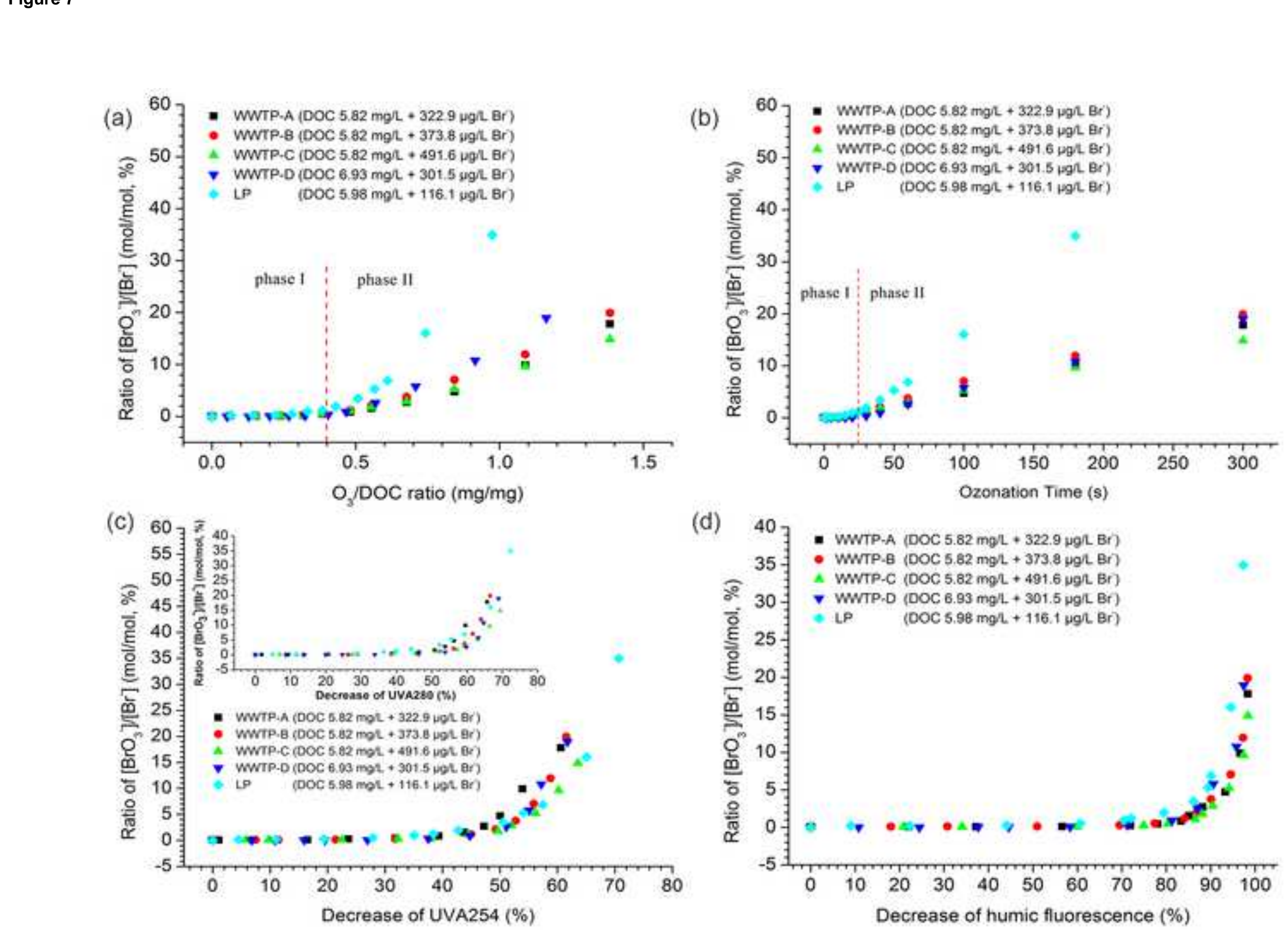

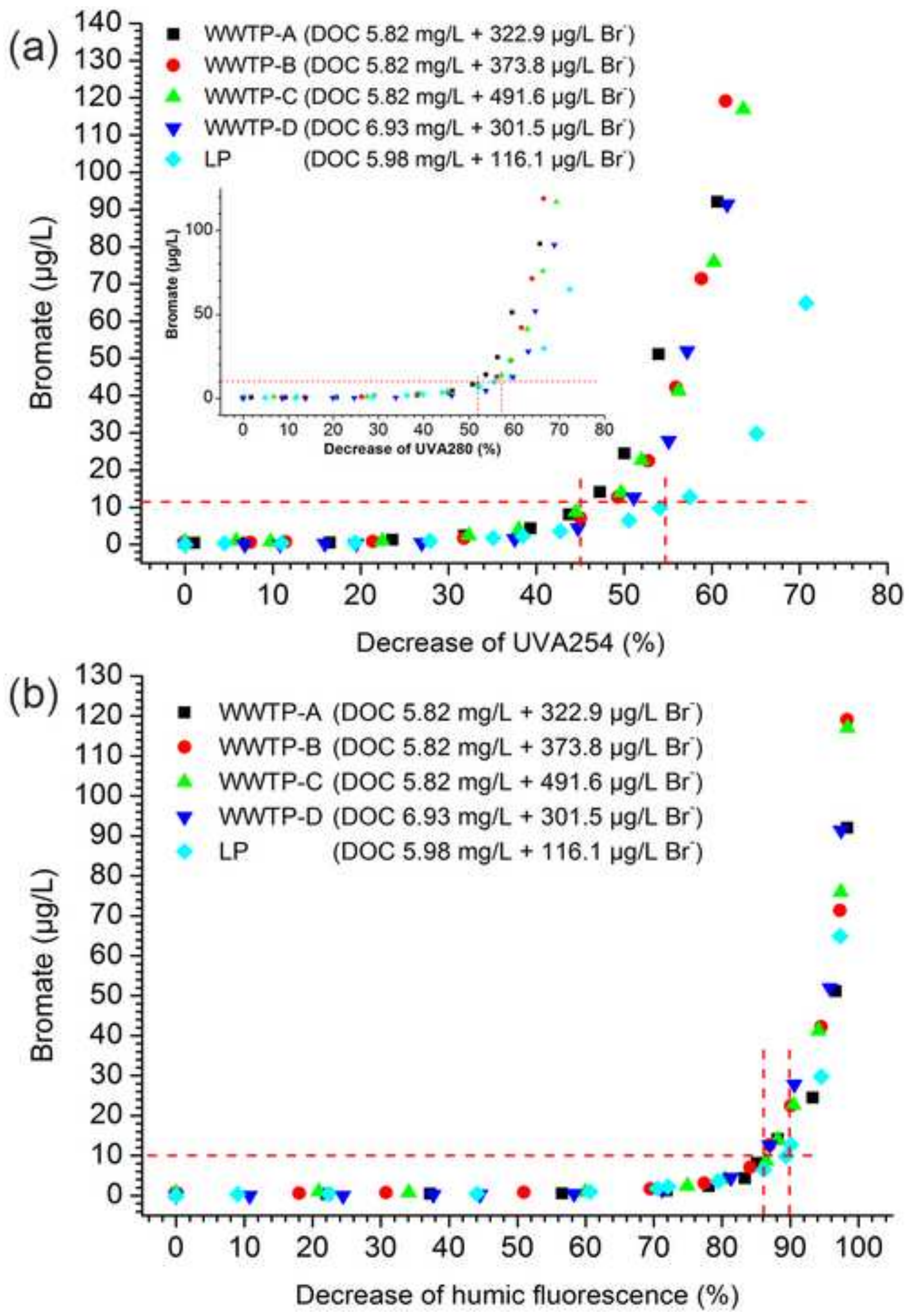